\title{
STRUKTUR KOMUNITAS IKAN KARANG PADA TEKNOLOGI ATRAKTOR MULTIFUNGSI DI PERAIRAN KAHYAPU, ENGGANO, BENGKULU
}

\section{COMMUNITY STRUCTURE OF REEF FISH IN THE MULTIFUNCTIONAL ATTRACTOR TECHNOLOGY IN THE KAHYAPU WATERS, ENGGANO, BENGKULU}

\author{
Zamdial, Nurlaila Ervina Herliany, Wahyu Nurmansyah, Ali Muqsit \\ Program Studi Ilmu Kelautan, \\ Fakultas Pertanian, Universitas Bengkulu \\ Korespondensi: zamdial_et@yahoo.co.id
}

\begin{abstract}
Multifunctional attractor technology is a technology of enriching fish resource stock in a water. This research aims to calculate and analyze the structure of coral fish communities associated in the waters of Kahyapu Village, Enggano Island, Bengkulu. The research was conducted in March-April 2020. The data was collected using Underwater Visual Census (UVC) techniques and underwater camera using SCUBA equipment. The method used in this study was a survey method. The relationship between reef fish abudance and immersiontime in multifunction attractor technology was analyzed by simple linier regression. It found 1.041 individuals from 43 species of 15 coral fish families associated with, consisting of 13 target fish species, 5 species of indicator fish, and 25 species of major fish groups. The composition of the species was found species with highest number of individuals from Dascyllus trimaculatus of $11,82 \%$. Abundance of coral fish $(\mathrm{X})$ amounts to 1,19 individuals $/ \mathrm{m}^{3}$. The value of the diversity index was ( $\left.\mathrm{H}^{\prime}\right) 3,25$. The evenness index (E) value was 0,863 . Meanwhile, the dominant index value $(C)$ was in the range of $0,0019-0,2363$. The value of the three indexes are high diversity and evenness but no fish dominates. The result of a simple linear regression analysis was $\mathrm{Y}=1,3639 \mathrm{x}+130,89\left(\mathrm{R}^{2}=0,0807, \mathrm{r}=0,284, \mathrm{~F}=0,439\right.$, and Ftable=6,61). Water parameters at the research location are very suitable for the life of coral biota.
\end{abstract}

Keywords: community structure, Enggano Island, reef fish

\begin{abstract}
ABSTRAK
Teknologi Atraktor Multifungsi (TAM) merupakan teknologi pengkayaan stok sumberdaya ikan pada suatu perairan. Penelitian ini bertujuan untuk menghitung dan menganalisis struktur komunitas ikan karang yang berasosiasi dengan TAM di Perairan Desa Kahyapu, Pulau Enggano, Bengkulu. Penelitian dilakukan pada bulan Maret-April 2020. Metode yang digunakan dalam penelitian ini adalah metode survei. Data dihimpun dengan menggunakan teknik Underwater Visual Census (UVC) dan kamera bawah air menggunakan peralatan SCUBA. Hubungan kelimpahan ikan karang dan lama penenggelaman TAM dianalisis dengan regresi linier sederhana. Ditemukan 1.041 individu dari 43 spesies dalam 15 famili ikan karang yang berasosiasi dengan TAM, terdiri dari 13 spesies ikan target, 5 spesies ikan indikator, dan 25 spesies kelompok ikan mayor. Komposisi Jenis $(\mathrm{KJ})$ ditemukan spesies dengan jumlah individu terbanyak dari Dascyllus trimaculatus yaitu 11,82\%. Kelimpahan ikan karang (X) sebesar 1,19 individu/ $\mathrm{m}^{3}$. Nilai indeks keanekaragaman (H') 3,25. Nilai indeks keseragaman (E) 0,863. Nilai indeks dominansi (C) kisaran 0,0019-0,2363. Dari nilai ketiga indeks menunjukkan keanekaragaman dan keseragaman yang tinggi tetapi tidak ada spesies ikan yang mendominasi. Hasil analisis regresi linier sederhana yaitu $Y=1,3639 x+130,89, R^{2}=0,0807, r=0,284$, Fhitung=0,349, dan Ftabel=6,61. Parameter perairan pada lokasi penelitian sangat cocok dengan kehidupan biota karang.
\end{abstract}

Kata kunci: ikan karang, Pulau Enggano, struktur komunitas 


\section{PENDAHULUAN}

Pulau Enggano adalah salah pulau terluar di Indonesia dan menjadi hunian manusia. Belum diketahui secara pasti, sejak kapan manusia mendiami pulau seluas $39.586,74 \mathrm{Ha}$ yang secara administrasi adalah salah satu kecamatan di Kabupaten Bengkulu Utara (Regen 2011). Pulau Enggano secara geologis adalah pulau samudra dan menurut sejarah geologinya tidak pernah bergabung dengan daratan Sumatera (LIPI 2017). Perairan Enggano memiliki kekayaan sumber daya pesisir yang sangat melimpah, mulai dari mangrove, lamun hingga terumbu karang yang sangat luas. Kondisi ekosistem terumbu karang di Kawasan Pulau Enggano tergolong dalam kondisi baik dan cukup baik. Berdasarkan pendekatan teori Caesar (1996), maka sumberdaya ikan yang dapat dimanfaatkan oleh masyarakat dari ekosistem terumbu karang di Kawasan Pulau Enggano adalah sebesar : 509,7 $\mathrm{km}^{2} \times 13$ ton ikan $/ \mathrm{km}^{2}$ / tahun $=6.626,1 \mathrm{ikan} / \mathrm{km}^{2} /$ tahun (Zamdial et al. 2019).

Upaya restoking sumberdaya ikan pada suatu perairan dapat dilakukan dengan pembuatan habitat alami yang telah rusak. TAM merupakan penggabungan teknologi pengkayaan stok sumberdaya ikan antara atraktor cumi dan fish apartement sehingga Teknologi Atraktor Multifungsi (TAM) merupakan sebuah inovasi baru yang diharapkan dapat menjadi ekosistem baru pada suatu perairan menjadi habitat bagi ikan dan cumi-cumi. Pemasangan TAM dalam perairan akan berperan sebagai terumbu karang buatan (artificial reef), berfungsi sebagai teknologi pengkayaan stok perairan yaitu alat pengumpul dan tempat cumi-cumi melepaskan telurnya juga sebagai habitat baru bagi ikan. Sudrajat (2019) menyatakan keberadaan atraktor cumi-cumi pada suatu perairan terbukti sangat efektif sebagai sarana menempelnya telur cumi-cumi, dan sebagai artificial reef yang menjadi daerah baru bagi tempat ikan, karang lunak, dan makroalga sehingga menjadi suatu ekosistem baru di suatu perairan. Sehingga diharapkan pemasangan TAM ini pada suatu kawasan perairan akan menciptakan pemandangan bawah air yang unik, yaitu pemandangan hamparan telur cumi-cumi dan juga dapat menjadi daerah asuhan, pembesaran, dan penyedia makanan alami bagi ikan, yang pada akhirnya dapat berkembang menjadi daerah penangkapan yang potensial.
Manfaat TAM sebagai artificial reef yang menjadi daerah baru bagi tempat ikan, karang lunak, dan makroalga perlu dipertahankan dengan persyaratan bahan yang dipergunakan terutama kerangka atraktor cumi-cumi harus memenuhi persyaratan dasar material terumbu karang buatan. Oleh karena itu, penelitian ini perlu dilakukan untuk mengetahui ikan yang berasosiasi dengan TAM dan menggambarkan habitat disekitarnya, sehingga dapat menjadi acuan untuk penelitian yang akan dilakukan pada masa mendatang. Tujuan dari penelitian ini untuk menghitung dan menganalisis jenis dan struktur komunitas ikan karang yang berasosiasi dengan TAM di Perairan Kahyapu Pulau Enggano.

\section{METODE PENELITIAN}

\section{Lokasi dan waktu penelitian}

Penelitian ini telah dilaksanakan di Desa Kahyapu, Kecamatan Enggano, Bengkulu Utara, pada bulan Maret-April 2020. Peta lokasi penelitian dapat dilihat pada Gambar 1.

\section{Prosedur kerja}

Pengamatan dan perhitungan jumlah ikan dilakukan per 3 hari setelah TAM ditenggelamkan. Pengamatan ikan yang berasosiasi dengan TAM dilakukan dengan pengulangan sebanyak 7 kali, dengan kelipatan per 3 hari pengamatan. Pengamatan ikan yang berasosiasi dengan TAM menggunakan metode Underwater Visual Census (Cappenberg 2009), dengan melakukan penyelaman menggunakan alat SCUBA dan menggunakan kamera bawah air (underwater camera) untuk mendokumentasikan biota yang berasosiasi dengan TAM. Data ikan diambil dengan mengidentifikasi jenis ikan yang terdapat di radius 2,5 meter dari titik penelitian termasuk tinggi 5 meter dari dasar titik penenggelaman TAM. Ikan-ikan yang berorientasi dengan TAM dan ditemukan dengan spesies yang sama hingga akhir pengamatan dianggap berasosiasi dengan TAM. Desain pengamatan ikan dapat dilihat pada Gambar 2.

Hasil dokumentasi menggunakan underwater camera inilah yang selanjutnya akan dilakukan pengamatan dan perhitungan jumlah ikan pada TAM. 
Pencatatan dilakukan pada lembaran 'censussheet' yang selanjutnya individu dari ikan-ikan tersebut akan diidentifikasi dan dikelompokkan berdasarkan famili dengan mengacu pada White et al. (2013), Fischer \& Whitehead (1974), Allen (1999), Bianchi (1985), McMillan et al. (2011), dan Kuiter \& Tonozuka (2001).

\section{Metode}

Metode yang digunakan dalam penelitian ini adalah metode survei, pengamatan, dan pengukuran langsung di lapangan. Menurut Notoatmodjo (2002), di dalam metode survei, penelitian tidak dilakukan pada seluruh objek yang dikaji, tetapi hanya mengambil dari sebuah populasi (sampel).

\section{Lingkup penelitian}

Jenis data yang digunakan dalam penelitian ini adalah data primer dan data sekunder. Data primer meliputi pengamatan ikan karang yang berasosiasi dengan TAM dan data pengukuran parameter perairan. Data sekunder yang diambil dari penelitian terdahulu di Pulau Enggano.

\section{Bentuk dan bahan TAM}

Konstruksi TAM terdiri dari gabungan antara atraktor cumi-cumi yang pada bagian sisi bawah diikatkan pada fish apartment. Rangkaian TAM terdiri atas satu buah atraktor dan pada sisi bawah diikatkan dengan dua buah fish apartment pada sisi panjang atraktor. Atraktor dirangkai dengan fish apartment pada bagian sisi bawah setelah ditenggelamkan. Selain berfungsi sebagai terumbu buatan, fish apartment dalam penelitian ini juga berfungsi sebagai pemberat agar atraktor yang ditenggelamkan pada perairan tidak hanyut terbawa arus. Jumlah TAM yang dipergunakan sebanyak 3 buah. Desain TAM dapat dilihat pada Gambar 3.

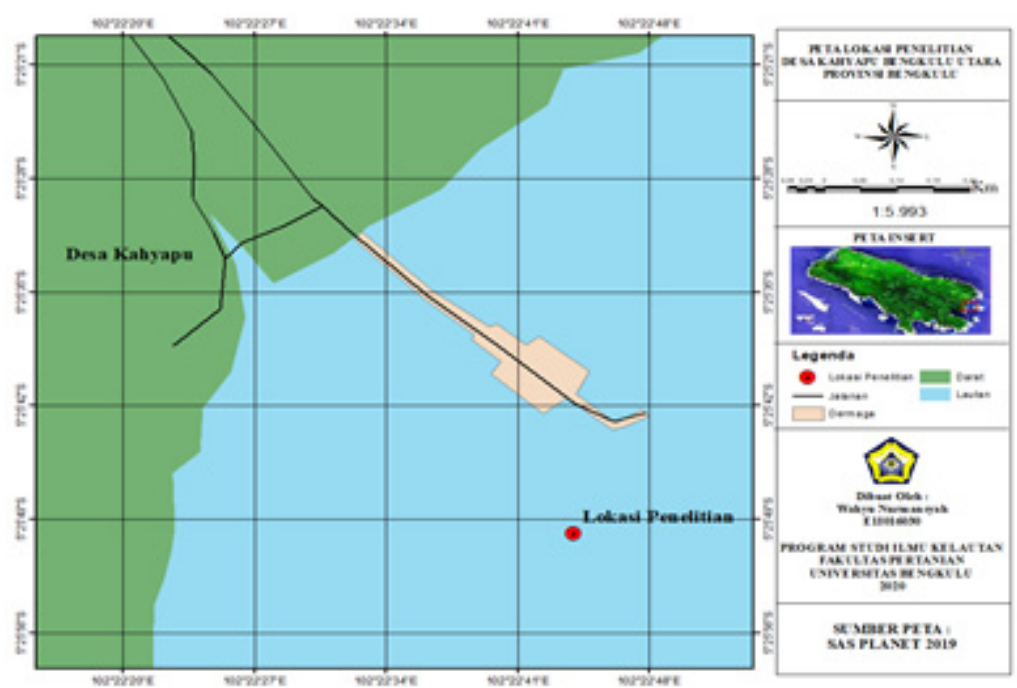

Gambar 1. Peta lokasi penelitian (peta insert: SAS PLANET 2019)

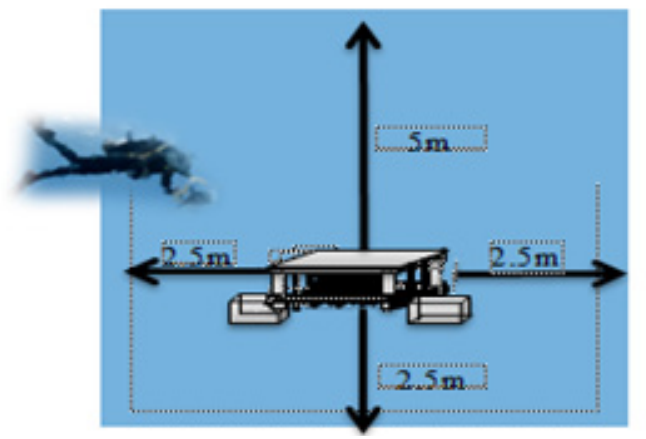

Gambar 2. Desain pengamatan ikan 


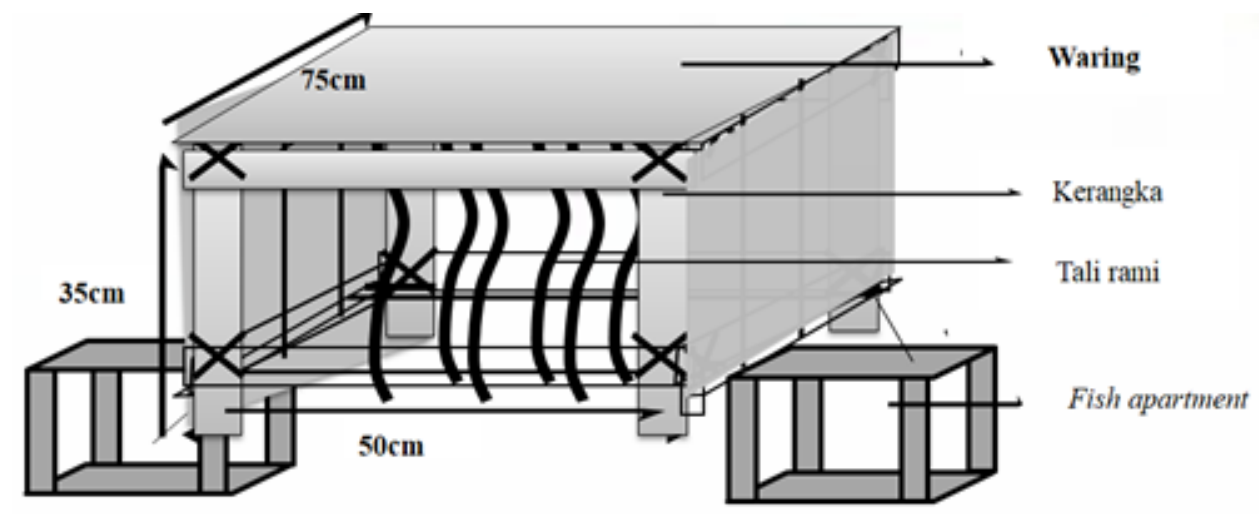

Gambar 3. Desain TAM

Keterangan:

Ukuran atraktor $75 \mathrm{~cm}$ x $50 \mathrm{~cm}$ x 35 $\mathrm{cm}$ berbahan kerangka dari baja ringan. Atraktor dilengkapi dengan tali rami yang berdiri vertikal pada bagian tengahnya dan bagian sisi atas, sisi kiri, dan sisi kanan ditutupi waring. Ukuran fish apartment 30 $\mathrm{cm} \times 30 \mathrm{~cm} \times 20 \mathrm{~cm}$ dengan bahan semen cor.

\section{Desain pemasangan TAM}

Rangkaian TAM ditenggelamkan pada kedalaman 7 meter pada saat kondisi surut pada daerah yang memenuhi kriteria habitat cumi-cumi yang dekat dengan ekosistem terumbu karang. Menurut Hasmawati dan Sugiarti (2014), atraktor efektif digunakan sebagai tempat penempelan telur cumicumi di perairan pada kedalaman 7 meter dan diletakkan berdampingan sejajar garis pantai dengan jarak 5 meter antar TAM. Desain Penempatan TAM dapat dilihat pada Gambar 4.

\section{Struktur komunitas ikan}

Komposisi jenis

KomposisiJenis ikan yang berasosiasi dengan TAM dihitung menggunakan rumus (Greenberg 1989):

$$
K J=\frac{n i}{N} \times 100 \%
$$

Keterangan :

$K J=$ Komposisi jenis

$n i=$ Jumlah individual jenis ikan

$N=$ Jumlah individu seluruh jenis
Kelimpahan ikan

Kelimpahan adalah banyaknya jumlah individu tiap jenis yang ditemukan pada luas daerah pengamatan. Kelimpahan ikan karang dapat dihitung dengan menggunakan rumus (Odum 1971):

$$
X=\frac{\sum X i}{n}
$$

Keterangan :

$X=$ Kelimpahan ikan

$X i=$ Jumlah ikan pada lokasi

$n=$ Luas transek pengamatan $\left(\mathrm{m}^{2}\right)$

\section{Indeks keanekaragaman}

Keanekaragaman jenis dihitung menggunakan indeks keanekaragaman Shannnom-Winner (Odum 1993). Indeks keanekaragaman digunakan untuk mendapatkan gambaran populasi organisme secara matematis (Odum 1993). Perhitungan ini dapat mempermudah analisis informasi jumlah individu masing-masing spesies dalam suatu komunitas ikan karang keanekaragaman dapat dihitung dengan rumus sebagai berikut:

$$
H^{\prime}=-\sum P i \ln (P i), \operatorname{dimana} P i=(n i / N)
$$

Keterangan :

$H^{\prime}=$ Indeks keanekaragaman jenis Shannon-Weiner

$n i=$ Jumlah individual jenis ikan

$N=$ Jumlah individu seluruh jenis

Kategori penilaian indeks H' menurut Odum (1971) dapat dilihat pada Tabel 1. 


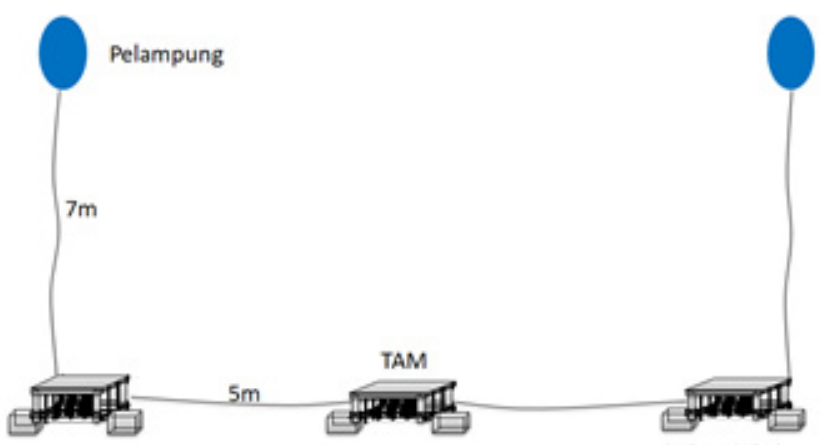

Gambar 4. Desain penempatan TAM

Tabel 1. Kategori indeks keanekaragaman

\begin{tabular}{ll}
\hline \multicolumn{1}{c}{ Nilai H' } & \multicolumn{1}{c}{ Industri Pengolahan Ikan } \\
\hline $\mathrm{H}^{\prime} \leq 1$ & Keanekaragaman rendah, penyebaran rendah, kestabilan komunitas rendah \\
$1 \leq \mathrm{H}^{\prime} \leq 3$ & Keanekaragaman sedang, penyebaran sedang, kestabilan komunitas sedang \\
$\mathrm{H}^{\prime} \geq 3$ & Keanekaragaman tinggi, penyebaran tinggi, kestabilan komunitas tinggi \\
\hline
\end{tabular}

\section{Indeks keseragaman}

Pengujian juga dilakukan dengan pendugaan indeks keseragaman $(E)$, dimana semakin besar nilai $E$ menunjukkan kelimpahan yang hampir seragam dan merata antar spesies (Odum 1971). Adapun rumus dari indeks keseragaman $(E)$ yaitu:

$$
E=\frac{H^{\prime}}{H m a k S}=\frac{H^{\prime}}{\operatorname{Ln} S}
$$

Keterangan:

$E \quad=$ Indeks keseragaman

$H^{\prime} \quad=$ Indeks keanekaragaman

$S \quad=$ Jumlah jenis

Hmaks = Indeks keanekaragaman maksimum

Adapun kriteria nilai indeks keseragaman sebagai berikut (Odum 1971):

$0<\mathrm{E} \leq 0,4 \quad$ : Komunitas tertekan

$0,4<\mathrm{E} \leq 0,6$ : Komunitas labil

$0,6<\mathrm{E} \leq 1 \quad$ :Komunitas stabil

Indeks dominansi

Rumus indeks dominansi Simpson (C) menurut Margalef (1958) dalam Odum (1983) yaitu:

$$
C=\sum(n i / N)^{2}
$$

dimana:

$C=$ Indeks dominansi Simpson

$n i=$ Jumlah individu spesies ke- $i$

$N=$ Jumlah individu seluruh spesies
Terdapat tiga kategori indeks dominansi, dapat dilihat pada Tabel 2.

Tabel 2. Kategori Indeks Dominansi

\begin{tabular}{cc}
\hline Dominansi (C) & Kategori \\
\hline $0,00<\mathrm{C} \leq 0,50$ & Rendah \\
$0,50<\mathrm{C} \leq 0,75$ & Sedang \\
$0,75<\mathrm{C} \leq 1,00$ & Tinggi \\
\hline
\end{tabular}

Sumber: Bakhtiar et al. (2012)

\section{Analisis regresi}

Data struktur komunitas ikan karang dianalisis dengan analisis regresi. Analisis regresi dilakukan apabila hubungan dua variabel mempunyai hubungan kausal atau fungsional. Persamaan umum regresi linier sederhana (Sugiyono 2007) :

$$
Y=a+b x
$$

Keterangan :

$Y$ : Subyek dalam variabel dependen yang diprediksi (kelimpahan ikan karang)

$x$ : Subyek dalam variabel independen yang mempunyai nilai tertentu (lama penenggelaman TAM)

$a$ : Harga $Y$ bila $X=0$ (harga konstanta)

$b$ : Angka arah atau koefisien regresi, yang menunjukkan angka peningkatan ataupun penurunan variabel dependen. Bila $b(+)$ maka naik dan bila (-) maka terjadi penurunan

Dasar pengambilan keputusan yaitu dengan membandingkan nilai $\mathrm{F}$ tabel 
dengan nilai $\mathrm{F}$ hitung.

Jika nilai $\mathrm{F}$ hitung $<\mathrm{F}$ tabel maka variabel $\mathrm{x}$ tidak berpengaruh terhadap variabel $\mathrm{y}$. Jika nilai $\mathrm{F}$ hitung $>\mathrm{F}$ tabel maka variabel $\mathrm{x}$ berpengaruh terhadap variabel $\mathrm{y}$.

Hasil dari perhitungan analisis dan pengambilan keputusan digunakan untuk menjawab hipotesis, yaitu Ho bahwa lama penenggelaman TAM tidak mempengaruhi kelimpahan ikan karang dan Ha bahwa lama penenggelaman TAM mempengaruhi kelimpahan ikan karang.

\section{HASIL DAN PEMBAHASAN}

Pada penelitian di Desa Kahyapu Pulau Enggano dengan tujuh kali pengambilan data didapatkan 5 ordo, 15 famili, 27 genus, 42 spesies, dan 936 individu ikan. Dari hasil penelitian, sebaran spesies ikan yang berasosiasi dengan TAM dapat dilihat pada Tabel 3 dan kelimpahan ikan selama pengamatan dapat dilihat pada Tabel 4.

Data dari pengamatan awal hingga akhir penelitian memiliki tren meningkat. Peningkatan jumlah individu ini mengindikasikan Teknologi Atraktor Multifungsi tempat yang baik untuk tempat asosiasi ikan. Hal ini sejalan yang dikatakan Manembu et al. (2014) bahwa kenaikan jumlah individu tentu saja merupakan indikator yang baik bagi ekosistem terumbu karang. Peningkatan jumlah ikan yang berasosiasi pada atraktor cumi-cumi dikarenakan semakin lama atraktor cumi-cumi berada di perairan maka akan semakin banyak menempelnya hydrozoans pada bagian kerangka, tali, dan penutup atraktor cumi-cumi sebagai bahan makan bagi biota karang yang berasosiasi. Sesuai dengan yang dikatakan Rani et al. (2010) ikan karang merupakan salah satu kelompok hewan yang berasosiasi dengan terumbu karang, keberadaannya mencolok dan ditemukan pada berbagai mikrohabitat di terumbu karang. Ikan karang hidup menetap dan mencari makan di area terumbu karang (sedentary), sehingga apabila terumbu karang rusak atau hancur maka ikan karang juga akan kehilangan habitatnya.

\section{Ikan target}

Kelompok ikan target yang dijumpai sebanyak 13 jenis yang terdiri dari famili
Siganidae (1 jenis), Acanthuridae (2 jenis), Lutjanidae (1 jenis), Mullidae (2 jenis), Nemipteridae (2 jenis), Scaridae (3 jenis), Serranidae (2 jenis). Russ dan Alcala (1989) mengemukakan bahwa kekayaan jenis (speciesrichness) ikan target dari kelompok pemangsa ikan-ikan kecil (piscivores) seperti Serranidae, Lutjanidae, Lethrinidae, dan Carangidae menjadi rendah akibat aktivitas penangkapan intensif. Beberapa jenis yang paling menonjol dari kelompok ikan target adalah Ctenocaetus striatus, Clorurus sordidus, Parupeneus indicus, dan Scolopsis bilineata.

\section{Ikan indikator}

Kelompok ikan indikator yang dijumpai dari famili Chaetodontidae (5 jenis). Ikan Chaetodontidae tergolong kelompok famili penting dan banyak dipelajari tentang kehidupannya di karang (Williams dan Hatcher 1983). Reese (1981) dan Hourigan et al. (1988) mengemukakan bahwa ikan-ikan kelompok famili Chaetodontidae memiliki asosiasi yang kuat dengan karang dan dapat digunakan sebagai indikator kesehatan karang. Selama penelitian dilaksanakan, ikan Chaetodontidae yang ditemukan sebanyak 5 jenis dari 2 genus. Beberapa jenis yang paling banyak ditemukan yaitu Chaetodon colare, Chaetodon vagabundus, dan Chaetodon trivasciatus.

\section{Ikan mayor}

Kelompok ikan mayor yang dijumpai sebanyak 24 jenis yang terdiri dari famili Pomacentridae (7 jenis), famili Labridae (8 Jenis), famili Pomacanthidae (4 jenis), famili Blenidae (1 jenis), famili Cirhitidae (1 jenis), famili Tetraodontidae (1 jenis), dan famili Pinguipedidae (2 jenis) juga ditemukan berasosiasi dalam teknologi atraktor multifungsi. Ditemukan juga beberapa jenis ikan yang berwarna tubuh yang indah sehingga berpotensi dimanfaatkan penggemar ikan hias (ikan aquarium) atau untuk atraksi wisata selam (Adrim et al. 2012). Beberapa jenis yang paling dominan ditemukan dari kelompok ikan mayor yaitu Dascilus trimaculatus, Chrysiptera talboti, Chrysiptera parasema, Halichoeres hortulanus, Halichoeres marginatus, dan Labroides dimidiatus. Beberapa spesies ikan berwarna indah dapat dilihat pada Gambar 5 . 
Tabel 3. Sebaran spesies ikan yang berasosiasi dengan TAM

\begin{tabular}{|c|c|c|c|}
\hline Order & Family & Genus & Spesies \\
\hline Blenniiformes & Blenniidae & Meiacanthus & Meiacanthus abruptus \\
\hline \multirow{11}{*}{ Labriformes } & \multirow{8}{*}{ Labridae } & Coris & Coris batuensis \\
\hline & & \multirow{4}{*}{ Halichoeres } & Halichoeres hortulanus \\
\hline & & & Halichoeres marginatus \\
\hline & & & Halichoeres cosmetus \\
\hline & & & Halichoeres nebulosus \\
\hline & & \multirow{2}{*}{ Labroides } & Labroides bicolor \\
\hline & & & Labroides dimidiatus \\
\hline & & Thalassoma & Thalassoma lunare \\
\hline & \multirow{3}{*}{ Scaridae } & \multirow{2}{*}{ Chlorurus } & Chlorurus sordidus \\
\hline & & & Chlorurus capistratoides \\
\hline & & Scarus & Scarus schlegeli \\
\hline \multirow{27}{*}{ Perciformes } & \multirow{2}{*}{ Acanthuridae } & Acanthurus & Acanthurus nigricans \\
\hline & & Ctenochaetus & Ctenochaetus striatus \\
\hline & Cirrhitidae & Paracirrhites & Paracirrhites forsteri \\
\hline & \multirow{5}{*}{ Chaetodontidae } & \multirow{4}{*}{ Chaetodon } & Chaetodon vagabundus \\
\hline & & & Chaetodon trifasciatus \\
\hline & & & Chaetodon collare \\
\hline & & & Chaetodon ephippium \\
\hline & & Heniocus & Heniocus singularius \\
\hline & Lutjanidae & Lutjanus & Lutjanus decussatus \\
\hline & \multirow{2}{*}{ Mullidae } & \multirow{2}{*}{ Parupeneus } & Parupeneus indicus \\
\hline & & & Parupeneus macronemus \\
\hline & \multirow{2}{*}{ Nemipteridae } & \multirow{2}{*}{ Scolopsis } & Scolopsis bilineata \\
\hline & & & Scolopsis affinis \\
\hline & \multirow{7}{*}{ Pomacentridae } & Amblyglyphidodon & Amblyglyphidodon aureus \\
\hline & & Chromis & Chromis opercularis \\
\hline & & & Chrysiptera talboti \\
\hline & & Chrysiptera & Chrysiptera parasema \\
\hline & & & Chrysiptera cyanea \\
\hline & & Dascyllus & Dascyllus trimaculatus \\
\hline & & Pomacentrus & Pomacentrus bankanensis \\
\hline & \multirow{4}{*}{ Pomachantidae } & Centropyge & Centropyge eibli \\
\hline & & \multirow{2}{*}{ Pomacanthus } & Pomacanthus imperator \\
\hline & & & Pomacanthus semicirculatus \\
\hline & & Pygoplites & Pygoplites diacanthus \\
\hline & \multirow{2}{*}{ Serranidae } & Epinephelus & Epinephelus faveatus \\
\hline & & Cephalopholis & Cephalopholis argus \\
\hline & Siganidae & Siganus & Siganus guttatus \\
\hline Tetraodontiformes & Tetraodontidae & Canthigaster & Canthigaster valentini \\
\hline \multirow{2}{*}{ Trachiniformes } & \multirow{2}{*}{ Pinguipedidae } & \multirow{2}{*}{ Parapercis } & Parapercis hexophtalma \\
\hline & & & Parapercis clathrata \\
\hline
\end{tabular}


Tabel 4. Jumlah ikan yang berasosiasi dengan TAM

\begin{tabular}{ccc}
\hline No & Pengambilan Data & Jumlah Ikan yang Berasosiasi (Ind) \\
\hline 1 & 1 & 158 \\
2 & 2 & 153 \\
3 & 3 & 131 \\
4 & 4 & 115 \\
5 & 5 & 127 \\
6 & 6 & 198 \\
7 & 7 & 164 \\
\hline \multicolumn{2}{c}{ Total } & 1.041 \\
\hline
\end{tabular}

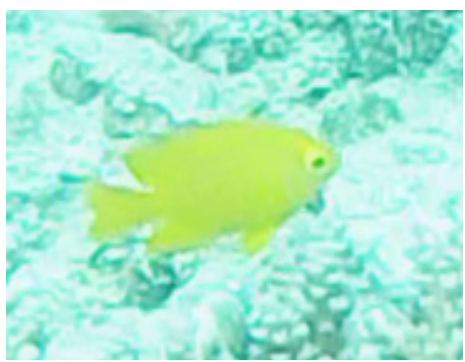

a

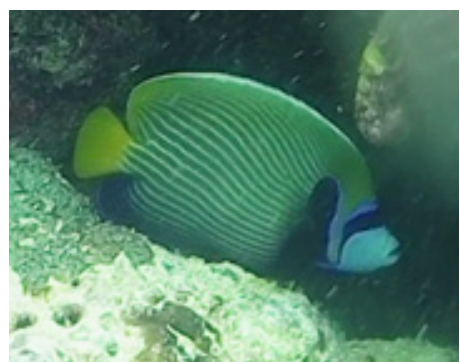

$\mathrm{b}$

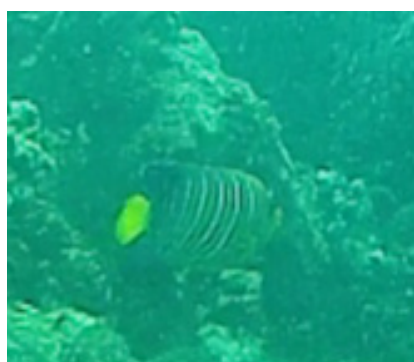

c

Gambar 5. Ikan yang terlihat indah (a. Amblyglyphidodon aureus, b. Pomacanthus imperator, c. Pygoplites diacanthus)

\section{Struktur komunitas ikan}

Komposisi jenis ikan tertinggi yang ditemukan saat penelitian yaitu famili Pomacentridae spesies Dascyllus trimaculatus dengan nilai $13,14 \%$. Menurut Rondonuwu dan Rembet (2013), tingginya nilai komposisi dari spesies tersebut dipengaruhi oleh tingginya persentase tutupan turf algae di lokasi pengamatan. Tingginya pertumbuhan turf algae dapat memicu kehadiran ikan herbivora salah satu contohnya adalah ikan Pomacentridae. Ikan dari famili Pomancentridae merupakan ikan yang memiliki jumlah jenis terbanyak serta merupakan kelompok ikan yang dominan dijumpai di perairan terumbu karang.

Kelimpahan ikan karang di lokasi penelitian yaitu $1,07 \mathrm{ind} / \mathrm{m}^{3}$. Menurut Dimara et al. (2020), jumlah individu ikan karang yang ditemukan di lokasi penelitian sangat berpengaruh terhadap tinggi rendahnya kelimpahan ikan karang. Secara tidak langsung, kondisi lingkungan seperti tutupan karang hidup juga sangat berpengaruh terhadap kelimpahan ikanikan yang hidup di terumbu karang tersebut. Kelimpahan spesies ikan karang tertinggi di lokasi penelitian adalah spesies Dascillus trimaculatus sebanyak 0,1406 ind $/ \mathrm{m}^{3}$. Spesies Dascyllus trimaculatus merupakan kelompok ikan mayor di terumbu karang dari famili Pomacentridae. Jumlah individu ikan mayor merupakan kelompok ikan karang yang memiliki kelimpahan yang tertinggi (Arham 2013). Adapun spesies dengan kelimpahan tertinggi selanjutnya yaitu Ctenocaetus striatus sebanyak 0,08 ind $/ \mathrm{m}^{3}$. Spesies Ctenochaetus striatus merupakan kelompok ikan target dari famili Acanthuridae. Tinginya kelimpahan spesies Ctenocaetus striatus dapat menandakan bahwa di lokasi tersebut dapat dijadikan daerah penangkapan ikan bagi nelayan sekitar. Sejalan dengan Dimara et al. (2020) tingginya kelimpahan ikan target (Ctenochaetus striatus) di stasiun Kampung Tua $\left(0,1333 \mathrm{ind} / \mathrm{m}^{2}\right)$ dan di Stasiun Serebo $\left(0,1867\right.$ ind $\left./ \mathrm{m}^{2}\right)$ menandakan bahwa kedua stasiun tersebut dapat dijadikan lokasi target penangkapan ikan bagi nelayan di sekitar lokasi penelitian.

Indeks keanekaragaman ikan karang yang didapatkan dilokasi penelitian yaitu $H^{\prime}=3,02$. Berdasarkan nilai indeks keanekaragaman ikan karangyang diperoleh, maka dapat disimpulkan bahwa dengan adanya teknologi atraktor multifungsi yang ditenggelamkan di lokasi penelitian, tingkat keanekaragaman ikan karang tergolong tinggi. Sesuai dengan pernyataan Odum (1971) yang menyatakan bahwa jika nilai 
H'>3 maka termasuk ke dalam kriteria keanekaragaman tinggi, penyebaran tinggi, dan kestabilan komunitas tinggi. Semakin besar nilai H' menunjukkan komunitas makin beragam. Hal ini menunjukkan rendahnya tekanan terhadap lingkungan di lokasi penelitian, baik dari lingkungan tempat organisme hidup maupun dari aktivitas manusia.

$$
\text { Indeks keseragaman }
$$

menggambarkan apakah sebaran jumlah individu masing-masing jenis diperoleh secara seragam atau tidak (Dimara et al. 2020). Nilai indeks keseragaman dari hasil pengolahan data yaitu 0,808. Berdasarkan nilai indeks keseragaman ikan karang yang diperoleh, maka dapat disimpulkan bahwa komunitas ikan karang di lokasi penelitian tergolong stabil. Odum (1971) menyatakan bahwa makin besar nilai $\mathrm{E}$ menunjukkan komunitas makin beragam. Sebagaimana pula dengan pernyataan Wilhm (1975) bahwa semakin tinggi nilai keseragaman menunjukkan keseragaman spesies yang tinggi, artinya kelimpahan spesies dapat dikatakan sama dan kecenderungan untuk didominasi oleh spesies tertentu sangat kecil.

Nilai indeks dominansi Simpson (C) dari hasil pengolahan data berkisar antara 0,0021-0,2628. Berdasarkan nilai indeks dominansi tersebut, dapat disimpulkan bahwa dengan adanya teknologi atraktor multifungsi dilokasi penelitian terdapat beberapa spesies ikan memiliki dominasi yang sangat tinggi dan terdapat beberapa spesies yang sangat rendah dominasinya. Menurut Odum (1971) bahwa kisaran indeks dominansi antara 0-1 dengan pengertian bahwa akan terjadi dominansi jenis jika nilainya mendekati atau sama dengan 1 dan sebaliknya. Semakin tinggi nilai indeks dominansi, maka kelimpahan suatu jenis yang ditemui akan terlihat jelas dibandingkan dengan jenis lainnya (Aziz 2004).

\section{Analisis regresi}

Berdasarkan hasil perhitungan analisis regresi linier sederhana didapatkan nilai $\mathrm{Y}=2,1735 \mathrm{x}+105,77$, yang mana 105,77 adalah nilai a dan 2,1735 adalah nilai b. Dari hasil tersebut, nilai $b$ yang merupakan koefisien regresi bernilai positif sehingga dapat disimpulkan bahwa terjadi peningkatan koefisien regresi berdasarkan lama waktu penenggelaman TAM. Dari hasil perhitungan tersebut didapatkan nilai koefisien determinasi $\left(R^{2}\right)$ yaitu 0,0807 . Sehingga maksud dari nilai $R^{2}=$ 0,322 adalah nilai lama penenggelaman TAM (variabel bebas) mempengaruhi nilai kelimpahan ikan karang (variabel terikat) sebesar $42,3 \%$, selebihnya $57,7 \%$ kelimpahan ikan dipengaruhi oleh faktor lain seperti kondisi lingkungan, parameter perairan, dan ketersediaan makanan. Didapatkan nilai koefisien relasi $(\mathrm{r})=0,651$ menunjukkan keeratan hubungan antara variabel lama penenggelaman dan variabel kelimpahan adalah sedang dan nilai positif menunjukkan bahwa hubungannya positif/ berbanding lurus yang artinya jika ada pertambahan lama penenggelaman maka terjadi pula pertambahan kelimpahan ikan karang. Grafik hubungan kelimpahan ikan karang dan lama penenggelaman TAM dapat dilihat pada Gambar 6 .

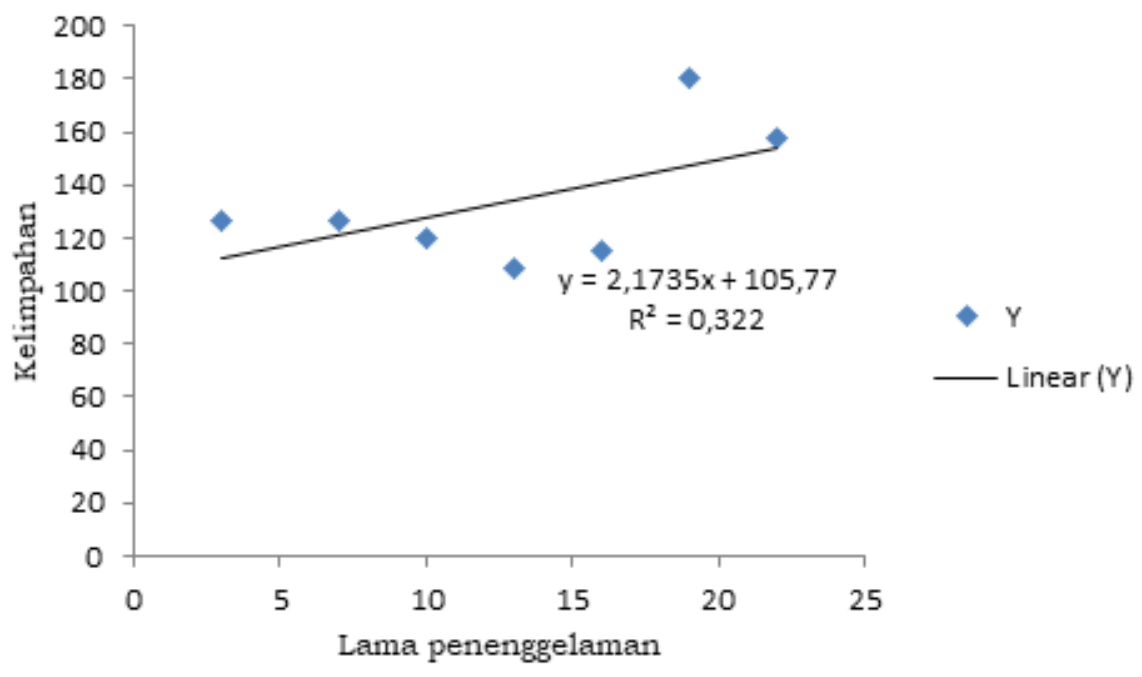

Gambar 6. Grafik hubungan kelimpahan ikan karang dengan lama penenggelaman TAM 
Hasil pengujian hipotesis ANOVA didapatkan nilai Ftabel $=7,71$ dan Fhitung $=2,94$. Sehingga nilai Fhitung $<$ Ftabel yang berarti bahwa lama penenggelaman TAM tidak berpengaruh terhadap kelimpahan ikan karang. Dari hasil pengujian ANOVA menjawab hipotesis (Ho) diterima yaitu tidak ada pengaruh lama penenggelaman TAM terhadap kelimpahan ikan karang yang berasosiasi dengan TAM. Hal ini diakibatkan dari lama waktu penenggelaman pada saat penelitian lebih cepat per 3 hari pengambilan data. Berbeda dengan penelitian Sudrajat (2019), dengan pengambilan data pertama dilakukan setelah 15 (lima belas) hari atraktor cumi-cumi setelah diletakan pada perairan. Hal ini dimaksudkan agar pada hari ke-15 ikan telah beradaptasi pada atraktor cumi-cumi. Selanjutnya selang waktu pengamatan tanggal 16 ke tanggal 23 (7 hari) juga dilakukan untuk mengetahui lamanya waktu atraktor cumi-cumi pada perairan dengan jumlah ikan.

Dapat disimpulkan bahwa dengan lama penenggelaman TAM pada suatu perairan tidak berpengaruh terhadap kelimpahan ikan karang. Memiliki nilai koefisien determinasi (pengaruh) lama penenggelaman TAM terhadap kelimpahan ikan sebesar 42,3\% dan nilai korelasi (hubungan) yang sedang tetapi bernilai positif/berbanding lurus yang artinya jika ada pertambahan lama penenggelaman maka terjadi pula pertambahan kelimpahan ikan karang. Sehingga penenggelaman TAM pada suatu perairan dapat menjadi habitat baru bagi ikan karang baik sebagai tempat mencari makan (feeding ground), tempat memijah (spowning ground), dan juga tempat berlindung (nursery ground). Semakin lama TAM ditenggelamkan, maka semakin banyak hidrozoans dan makro alga yang menempel pada rangka, tali, dan penutup dari atraktor yang mengindikasikan bahwa TAM menyediakan makanan bagi ikan karang.

\section{Parameter perairan}

Berdasarkan pengukuran parameter yang dapat dilihat pada Tabel 5 , rata-rata suhu perairan selama pengambilan data di lokasi penelitian berkisar antara $30-31^{\circ} \mathrm{C}$. Kisaran suhu yang didapat pada penelitian ini sangat baik bagi pertumbuhan dan kehidupan ikan karang yang berasosiasi disekitar TAM. Hal ini sesuai dengan pendapat Anwar et al. (1984) yang menyatakan bahwa kisaran suhu yang baik untuk ikan adalah antara $25-32^{\circ} \mathrm{C}$. Kisaran salinitas berdasarkan tabel berkisar antara 32,67-36,67\%o. Nilai salinitas tertinggi pada pengambilan data ketiga yaitu $36,67 \%$, pada saat pengambilan data dilakukan pada siang hari saat cuaca cerah dan panas terik sehingga tidak ada pengaruh dari air hujan dan membuat kadar salinitas perairan menjadi tinggi. Sedangkan pada pengambilan data terakhir ratarata salinitas $32,67 \%$, pengambilan data dilakukan setelah hujan sehingga salinitas air menjadi lebih rendah. Kecerahan air laut di lokasi penelitian berdasarkan tabel hasil pengukuran kecerahan $100 \%$ selama pengambilan data. Kecerahan perairan adalah $100 \%$ pada kedalaman 7 meter, perairan tersebut tergolong perairan yang masih bersih, dimana cahaya yang masuk ke perairan dapat menembus dengan sempurna hingga kedalaman $7 \mathrm{~m}$ (Rachmad et al. 2018). Parameter perairan selama penelitian menyatakan bahwa kisaran suhu dan salinitas yang sangat baik bagi pertumbuhan dan kehidupan ikan karang dan tergolong perairan yang masih bersih.

Tabel 5. Pengukuran parameter perairan

\begin{tabular}{cccc}
\hline & Suhu $\left({ }^{\circ} \mathbf{C}\right)$ & Salinitas (PPT) & Kecerahan (\%) \\
\hline Rata-rata & $30-31$ & $32,67-36,67$ & 100 \\
\hline
\end{tabular}

Sumber: Data Primer (2020)

\section{KESIMPULAN DAN SARAN}

\section{Kesimpulan}

Ditemukan 936 individu dari 42 spesies dalam 15 famili ikan karang yang berasosiasi dengan TAM di Perairan Desa Kahyapu Pulau Enggano. Telah dikelompokkan menjadi 13 spesies ikan target, 5 spesies ikan indikator, dan 24 spesies ikan mayor. Komposisi Jenis (KJ) tertinggi dari famili Pomacentridae spesies Dascyllus trimaculatus dengan nilai 13,14\%. Kelimpahan ikan karang (X) sebesar 1,07 individu $/ \mathrm{m}^{3}$. Indeks keanekaragaman (H') 3,03 dalam kategori keanekaragaman 
tinggi. Indeks keseragaman (E) tergolong tinggi dengan nilai 0,808 . Indeks dominansi (C) tergolong tinggi kisaran 0,0021-0,2628.

Analisis regresi linier sederhana didapatkan nilai $\mathrm{Y}=2,1735 \mathrm{x}+105,77$, yang mana koefisien regresi bernilai positif, lama penenggelaman TAM mempengaruhi kelimpahan ikan sebanyak 42,3\% dan memiliki hubungan yang sedang tetapi bernilai positif atau berbanding lurus. Hasil pengujian ANOVA menjawab hipotesis (Ho) diterima yaitu tidak ada pengaruh lama penenggelaman TAM terhadap kelimpahan ikan karang yang berasosiasi dengan TAM. Pengukuran parameter perairan meliputi suhu rata-rata $30-31{ }^{\circ} \mathrm{C}$, salinitas rata-rata $32,67 \%$ o-36,67\%o, dan kecerahan 100\%. Parameter perairan selama penelitian menyatakan bahwa kisaran suhu dan salinitas yang sangat baik bagi pertumbuhan dan kehidupan ikan karang dan kecerahan yang menunjukkan bahwa perairan masih bersih.

Sehingga penenggelaman TAM pada suatu perairan dapat menjadi habitat baru bagi ikan karang baik sebagai tempat mencari makan (feeding ground), tempat memijah (spowning ground), dan juga tempat berlindung (nursery ground). Semakin lama TAM ditenggelamkan, maka semakin banyak alga yang menempel pada atraktan, tali, dan penutup dari atraktor yang mengindikasikan bahwa TAM menyediakan makanan bagi ikan karang.

\section{Saran}

Hasil penelitian ini diharapkan dapat menjadi data acuan pengembangan teknologi pengkayaan sumber daya ikan yang dapat dilakukan dengan mudah dan peralatan yang murah tetapi kuat. Diharapkan ada penelitian lanjutan pada kedalaman berbeda, lama waktu penenggelaman, memperbanyak TAM yang ditenggelamkan, memperbesar ukuran TAM, berbeda lokasi penelitian, penambahan rumpon dasar, atau dengan gabungan teknologi pengkayaan stok yang lain sebagai struktur penyusun TAM, agar data mengenai TAM lebih kuat dan hasil lebih maksimal. Sehingga dapat menjadi referensi yang konkret yang dapat digunakan baik civitas akademika, pemerintah daerah (PEMDA), maupun masyarakat umum untuk menciptakan atau mengembangkan teknologi terbarukan sebagai media pengkayaan sumberdaya ikan dan sebagai terumbu karang buatan
(Artificial reef) pada suatu ekosistem perairan.

\section{UCAPAN TERIMAKASIH}

Penulis mengucapkan terima kasih kepada seluruh dosen dan staf Program Studi Ilmu Kelautan. Seluruh tim penelitian Pulau Enggano: Chris Meriya KN, Huanius Jastino Tresavaldo Quiko, Icencye Ayu Nickty Aziza, Jadihisar Ericsen Tambun, serta rekan-rekan yang telah membantu jalannya penelitian ini.

\section{DAFTAR PUSTAKA}

Adrim M, Harahap SA, Wibowo K. 2012. Struktur Komunitas Ikan Karang di Perairan Kendari. Jurnal Ilmu Kelautan. 17(3): 154-163.

Allen G. 1999. Marine Fishes of South-East Asia. Periplus Editions.

Anwar J, Whitten AJ, Damanik SJ, Nisyam N. 1984. Ekologi Ekosistem Sumatera. Yogyakarta: Gadjah Mada University Press.

Arham M. 2013. Status Ekologi Ikan Karang Kaitannya dengan Tutupan Makroalga dan Terumbu Karang di Pulau-Pulau Kecil Kabupaten Polman [Tesis]. Makassar: Universitas Hasanuddin.

Aziz AW. 2004. Studi Kelimpahan dan Keanekaragaman Ikan Karang Famili Pomacentridae dan Labridae pada Daerah Rataan Terumbu (Reef Flat) di Perairan Pulau Barrang Lompo. Makassar: Universitas Hasanuddin.

Bakhtiar D, Djamali A, Arifin Z, Sarwono T. 2012. Struktur Komunitas Ikan Karang di Perairan Pulau Tikus Kota Bengkulu. Prosiding Seminar Nasional dan Rapat Tahunan Bidang Ilmu-Ilmu Pertanian BKS-PTN Wilayah Barat, Medan.

Bianchi G. 1985. FAO Species Identification Sheets for Fishery Purposes. Field Guideto The Commercial Marine and Brackish-Water Species of Pakistan. Prepared with The Support of PAK/77/033 and FAO (FIRM) Regular Programme. Rome: FAO. $200 \mathrm{p}$.

Caesar H. 1996. Economic Analysis of Indonesia Coral Reef. Working Paper Series "Work in Progress". 
Washington DC: World Bank. 97 p.

Cappenberg HD. 2009. Monitoring Kesehatan Terumbu Karang Kabupaten Bintan (Pulau-pulau Tambelan). Jakarta: Coremap - LIPI.

Dimara M, Hamuna B, Kalor JD, Paulangan YP. 2020. Analisis Ekologi dan Kelimpahan Ikan Karang di Perairan Teluk Depapre, Kabupaten Jayapura. Jurnal Ilmu Kelautan dan Perikanan Papua. 3(1): 8-15.

Fischer W, Whitehead PJP. 1974. FAO Species Identification Sheets for Fishery Purposes. Eastern Indian Ocean (Fishing Area 57) and Western Central Pacific (Fishing Area 71). Volume 1.

Greenberg. 1989. Standard Methods for the Examination of Water and Waste water for 4th Edition. Washington: American Publich Health Assosiation.

Hasmawati, Sugiarti A. 2014. Efektivitas Atraktor terhadap Penempelan Telur Cumi-Cumi pada Kedalaman yang Berbeda. Jurnal Balik Diwa. 5(2): 26-33.

Hourigan TF, Tymothy CT, Reese ES. 1988. Coral Reef Fishes as Indicators of Environmental Stress in Coral Reefs. In: Dorothy FS \& GS Kleppel (Eds.). New York: Springer-Verlag New YorkInc. 107-135 pp.

Kuiter RH, Tonozuka T. 2001. Indonesian Reef Fishes. Part 1. Zoonetics. Australia.

[LIPI] Lembaga Ilmu Pengetahuan Indonesia. 2017. Ekspedisi Pulau Enggano. Jakarta: LIPI press.

Manembu I, Adrianto L, Bengen D, Yulianda F. 2014. Kelimpahan Ikan Karang pada Kawasan Terumbu Buatan di Perairan Ratatok Sulawesi Utara. Bawal. 6(1): 55-61.

McMillan PJ, Griggs LH, Francis MP, Marriott PJ, Paul LJ, Mackay E, Wood BA, Sui H, Wei F. 2011. New Zealand Fishes. Volume 3: A Field Guide to Common Species Caught by Surface Fishing. New Zealand Aquatic Environment and Biodiversity Report No. 69.

Notoatmodjo S. 2002. Metodologi Penelitian Kesehatan. Yogyakarta: Rineka Cipta.

Odum EP. 1971. Dasar-dasar Ekologi. Catatan ke-3. Yogyakarta: Gajah Mada University Press.

Odum EP. 1983. Basic Ecology. New York: Saunders College Publishing.
Odum EP. 1993. Dasar-dasar Ekologi. Terjemahan Tjahjono Samingan. Edisi Ketiga. Yogyakarta: Gadjah Mada University Press.

Rachmad B, Suharti R, Irayana DA, Zulkifli D. 2018. Distribusi Spasial Ikan Famili Scaridaedi Perairan Taman Nasional Bunaken, Sulawesi Utara. Jurnal Kelautan dan Perikanan Terapan. 1(2): 69-76.

Rani C, Burhanuddin AI, Atjo AA. 2010. Sebaran dan Keanekaragaman Ikan Karang di Pulau Barrangloppo: Kaitannya dengan Kondisi dan Kompleksitas Habitat. Makassar: Universitas Hasanuddin.

Reese ES. 1981. Predationon Corals by Fishesof The Family Chaetodontidae: Implications for Conservation and Management of Coral Reef Ecosystems. Bull. Mar. Sci. 31: 594604.

Regen R. 2011. Profil Kawasan Konservasi Enggano. (P.B. Bengkulu, Ed.). Bengkulu: BKSDA Bengkulu \& Enggano Conservation.

Rondonuwu AB, Rembet UNWJ. 2013. Ikan Karang Famili Chaetodontidae di Terumbu Karang Pulau Para Kecamatan Tatoareng Kabupaten Kepulauan Sangihe. Jurnal Ilmiah Platax. 1(4): 210-215.

Russ GR, Alcala AC. 1989. Effects of Intense Fishing Pressure on An Assemblage of Coral Reef Fishes. Mar. Ecol. Prog. Ser. 56: 13-27.

Sudrajat D, Baskoro MS, Zulkarnain, Yusfiandayani R. 2019. Asosiasi Ikan Karang pada Atraktor CumiCumi Berbahan Pipa PVC. Jurnal Ilmu dan Teknologi Kelautan Tropis. 11(2): 413-425.

Sugiyono. 2007. Statistika untuk Penelitian. Bandung: Alvabeta.

White WT, Last PR, Dharmadi, Faizah $\mathrm{R}$, Chodrijah U, Prisantoso BI, Pogonoski JJ, Puckridge M, Blaber SJM. 2013. Market Fishes of Indonesia $(=$ Jenis-Jenis Ikan di Indonesia). ACIAR Monograph No. 155. Canberra: Australian Centre for International Agricultural Research. $438 \mathrm{pp}$.

Wilhm JF. 1975. Biology Indicator of Pollution River Ecology. Oxford: Blackwell.

Williams DMcB, Hatcher AI. 1983. Structure of Fish Communities on Outer Slopes 
of Inshore, Mid-Shelf and Outer Shelf Reefs of the Great Barrier Reef. Mar. Ecol. Prog. Ser. 10: 239-250.

Zamdial, Hartono D, Anggoro A, Muqsit A. 2019. Valuasi Ekonomi Ekosistem Terumbu Karang di Pulau Enggano, Kabupaten Bengkulu Utara, Provinsi Bengkulu. Jurnal Enggano. 4(2): 160-173. 